Original Research Paper

\title{
A Review of the Fatigue Strength of Load Carrying Shear Welded Joints
}

\author{
${ }^{1}$ Filippo Berto, ${ }^{1}$ Abedin Gagani, ${ }^{2}$ Relly Victoria V. Petrescu and ${ }^{2}$ Florian Ion T. Petrescu \\ ${ }^{I}$ Department of Engineering Design and Materials, NTNU, Trondheim, Norway \\ ${ }^{2}$ ARoTMM-IFToMM, Bucharest Polytechnic University, Bucharest, (CE) Romania
}

Article history

Received: 22-09-2016

Revised: $29-12-2016$

Accepted: 31-12-2016

Corresponding Author:

Filippo Berto

Department of Engineering

Design and Materials, NTNU,

Trondheim, Norway

Email: berto@gest.unipd.it

\begin{abstract}
In the study it is shown an overview of the latest results of two types of joints of the load carrying welded shear. Tests of fatigue have been carried out on the two solutions specific design features proposed and with the aim of improving the resistance of the joints under cycling loading. By hiring the 3D models, was determined Strain Energy Density (SED), in a volume of control which surrounds the lowest point of interest. All of the experimental results have been presented in short. The synthesis shows that all data are within the range of the scattering of the proposed previously in the specialized literature for steel construction welded.
\end{abstract}

Keywords: Welded Joints, Fatigue Strength, Shear Loading, Local Approaches, Strain Energy Density

\section{Introduction}

The resistence under cycling loading of the welded connections is essentially a problem the effect of the notch, depending on the range of stress applied, common geometry and its dimensions. The areas the most critical moments in the case in which the cracks nucleate and spread are usually the weld toe and weld roots. This topic was studied extensively in the past. A body of data accumulated permits analysis of reliability, on the one hand and the formulation of a variety of assessment of resistance to fatigue approached on the other side.

Approach to the most common, which is often built into the codes or standards (C.F., Eurocode 3,15018, ASME, IIW and others), the official shall be based on the S-N curves. Since the fatigue life is here in connection with the range of nominal stress in crosssection critical, derived from external forces and moments applied, the concentrations of local stress are not taken into account in the explicitly, but they are taken into account from different reporting curved design for the different details of welding. In this way, the resistance to tiredness of a welded joints is correlated with its class of quality geometry, materials and welding. The effects of environments and residual tensions, multiaxiality stress, slab thickness and dressing the spot welds are taken into account in this approach (Radaj et al., 2006). Evaluations of resistance which take into account only the effects of external loads are well known under the terms of the global approaches or approaches to stress nominal.

The connection between the life of the fatigue of Joints welded to the local tensions to finger from no welding or root, the main issue is the definition of geometric parameters of the weld bead, such as the radius of the finger of the foot and the form of the heel (Livieri and Lazzarin, 2005; Lazzarin et al., 2003). These parameters may vary not only for the different faces of the same design, but also within the same interdiction; moreover the radius of the tep may be considered to be equal to zero or tends toward zero (Atzori, 1985; Lazzarin and Tovo, 1998).

Overcoming difficulties related to the correct definition of the value of the spot welds tep radius and form of the string of beads, structural approach hot spot separates the slope of the stress in the vicinity of the peak in two components: The first one is a linear gradient analysis obtained structural model shell of the main plates of the welded joint without taking into account the geometry of the weld to the heel; the second is a non-linear gradient caused by the presence of the weld toe. In this approach, the assessment of the service life of the fatigue is carried out on the basis of the stress linear gradient contributes to the extrapolated of peak of weld (stress hot spot), based on the assessment of the stress linear gradient contribute to some points of reference. In this method, while the distributions of the crisis obtained shall take into account the effect of 
macrogeometry, the effect of the scoring of welding is taken into account by reducing the curve $\mathrm{SN}$ : The approach is called the stress approach structural and acts as a link between the global approaches and local Radaj et al. (2006). The structural approach hot spot is used in some codes and documents for the design of the welded connections (Hobbacher, 2006).

As regards the global approaches opposite, local approaches to move from the stress or strain local parameters. In accordance with the parameters elected local and the criteria for the entered failure, it is possible to distinguish different versions of the local approach. Local processes of damage from fatigue materials are cyclical of initiation of the cracks, the propagation and the failure of the final. While the notch approach to stress or notch strain approach considers the process of initiation of the crack, approach of propagation of cracks considers that the propagation of a fracture of the existing incipient. In the local approaches, the worst case of parameters geometric parameters of weld is presumed Radaj et al. (2006).

In an approach to stress the notch, the effect of the scoring is fully taken into account, should be used for an absolute assessment of resistance to fatigue, referring to the life of infinite or to the limit of the durability test. In this case, fatigue initiation cracks must be avoided or at least the crack initiated must not propagate (cracks latency). When they are used for the assessment of the resistance to fatigue in the range of finite life, this approach should be combined with the stem approaches notch and spread of the cracks. It is worth to remember that the factor of concentration of the elastic stress and support the notch microstructural subjects are included in the approach of stress notch. critical distance (Susmel et al., 2013; Susmel and Taylor, 2012; 2011), a placeholder notch Roundings (Radaj et al., 2013; Berto et al., 2012; Radaj et al., 2009; Berto, 2016), as roundings notch (Karakas et al., 2008; 2007) and approaches of volume extremely stressed are a different version of the concept of stress notch. It is worth mentioning also approach the default gradient, applied for the evaluation of the fatigue of the components of the jagged and welded tasks at the fatigue the carrying out of the hinge (Cristofori et al., 2009; Tovo and Livieri, 2012; Maggiolini et al., 2015; Livieri et al., 2016).

Approach to stem the notch starts at the amplitudes of rubber strain-plastic ties at the root of the notch and they have compared with the curves of the stem SN a specimen unnotched of the same material, microstructure, the conditions of the surface and possibly as a volume in the region very pronounced in the recess of the root. Strain the root of the mark may be calculated or measured.

While the approaches to stress the notch and strain the notch are linked to the opening of a technical cracks, approach of propagation of cracks in the reference is made to the propagation of a fracture. In fact, in many cases, the presence of a crack can be tolerated, if its propagation is stable. This approach is used as a complement to develop approaches to stress the notch and the stem linked to the crack from which technical initiation has been evaluated previously by the approaches the notch, or in the case of existing cracks, cracking such as faults, goals or the louvers (e.g., the root of the weld is faced). This allows, for example, in order to define the size of the tolerable the faults and crack-faults, as it may be, the intervals of inspections in operation and the evaluation of the resistance to the residual fatigue a structure with a detectable crack existence (BS7608, 1993).

The analysis of the spread of the cracks is performed in terms of the mode I opening cyclic ratio the factor of intensity of $\Delta K_{I}$ voltage, in the case of fatigue medium or cycle of high, or with respect to the opening cyclic ratio J-integral, in the case of the voltages more and more elastic deformation on the tip of the fissure. Some recent examples of the use of the J-integral for the evaluation of the service life of the fatigue of the welded connections and prediction of static failures in sharp $\mathrm{V}$ notches and rounded U-nicks can be found in the (Frank et al., 2011; Remes et al., 2012; Frank et al., 2013; Livieri, 2008; Livieri and Tovo, 2009). Although this approach concerns only the Propagate phase of a fracture available, it is used to predict the values of the absolute value of resistance to fatigue or the service life of the welded connections of unconventional photos. In accordance with the recommendations of the United Kingdom and the European Communities, this approach is suitable for the classification of welded connections in unconventional standards $\mathrm{N}$ curve, in combination with a calibration (BS7608, 1993; ECCS/CECM/EKS, 1985). In this case, the receipts of analysis from small micro cracks $(0.1 \mathrm{~mm})$ to the finger of the foot of welding, without taking into account the phase of initiation of the crack: These micro cracks are either of them fictitious or present at the toe of weld, due to the manufacturing process, also in the form of faults and slag intrusions and subjected to the residual voltage high tension. This assessment of resistance to fatigue has not been universally accepted. In the welded joints of high quality, this existing microcracks, which spreads with the first charging cycle is not true in general. In accordance with the investigation's Lassen (1990) and Singh et al. (2003), phase nucleation crack can represent a large amount of total life to tiredness. Even if a microcrack is indeed present at your finger welding, it will propagate initially in the area of the notch distorts plastic: Parameter dominant rhythm of the spread of the crack will then be cyclic J-integral or the factor of intensity of the voltage notch, instead of the elastic 
stress the factor of intensity. The area of the peak plastic crack becomes the driving force only when the crack reaches a sufficient size. Radaj estimates that $90 \%$ of the time spent in order to get to a depth of the crack of $1 \mathrm{~mm}$ is linked to the spread of integrated microcracks initially in an area of the plastic, for which the pad factor cyclic ratio of intensity of $\Delta K_{I}$ voltage cannot be used (Radaj, 1990).

An approach based on factor of stress Notch Intensity (NSIF) has been proposed by Lazzarin and Tovo (1998) and for the prediction resistance to tiredness. This approach take into account both the form of welding string of beads (angle of the finger of the foot of welding, or the opening angle notch) and radius of the weld toe (notch peak radius). The radius of the tep may be equal to (notch sharp) zero, or may have a value of the finished (blunt notch). In both cases, the region around the peak notch (region tep weld) is characterized by the high voltages notch who have a singular behaviour in the case of nicks sharp. determined NSIFs pad (or, in the case of bigger tasks, spring plasticdetermined by stress the notch or factors of intensity strain) may describe the voltages of the region of toe of weld, quantifying the intensity of the distributions of stress on the basis of conditions of orders of the Williams solution (1952). NSIF approach was originally proposed to estimate the stage of initiation of the cracks (Boukharouba et al., 1995; Verreman and Nie, 1996), but only later was demonstrated later that NSIFs parameters are able to predict the service life of the fatigue of the welded connections (Livieri and Lazzarin, 2005; Lazzarin and Tovo, 1998; Atzori et al., 1999). In fact, a large quantity of life to fatigue for welded structural is spent at the depth of the crack in the short term, within the region governed by the singularities V-notch: Therefore, nucleation and increase the short cracks are dependent on the distributions of stress present in the component Nesfari-stopper. The original data from Maddox (1987) and Gurney (1991) for transverse load without carrying the file welded joint faces have been retested the Lazzarin and Tovo (1998). The original S-data $\mathrm{N}$ has been largely wasted, because of the large variation of the parameters geometric parameters of the joints. In spite of this large variability, scattering has been greatly reduced using NSIF approach.

NSIFs dimensionality depends on the angle of the opening with the notch in the $\mathrm{V}$ : Varying the angle, it is not possible to make a direct comparison as regards amounts NSIFs. This means that it is not possible to make a comparison between the welded joints with different angles of weld toe and between the root of the weld and tep same faces NSIFs values which compares directly with the aim of identifying the area the most critical for the life of the fatigue the joint. In order to overcome this issue, the stress factors of intensity notch can be used to derive the other criteria failures, by defining the J-drive, on average energy density stem and the actual voltages to the well of the corner (Radaj et al., 2006).

An approach based on the density of the Stem of Energy Medium (SED) $\Delta \mathrm{W}$, calculated on a volume of a control that surrounds the base of the welding or root, was proposed by Lazzarin and Zambardi (2001). As mentioned above, using the approach EDI, the comparability between the notches with different opening angles is re-established, being the unit of measure independent of the geometry of the notch. More than that, it is possible to take into account the terms of the order of more than distributions of stress, which are not taken into account in his solutions Williams, such as T-stress (Lazzarin et al., 2009) and effects and threedimensional singularities out-of-plan (Berto and Lazzarin, 2014; Berto and Lazzarin, 2009). Finally, the EDI value in a volume control can be determined with great accuracy using mesh coarse, as opposed to the evaluation of the NSIFs, which needs mesh very fine (Lazzarin et al., 2010; 2008a;). According to this criterion, insufficient fatigue appears when the average value of the SED calculated in a volume cylindrical sector of the radius $\mathrm{r} 0$ around the top notch reach a value critical. The radius $\mathrm{r} 0$ is a parameter of the characteristic material and shall be assumed to be independent of the load mode. For welded joints, the values of the radius $\mathrm{r} 0$ proved to be $0.28 \mathrm{~mm}$ for steel and $0.12 \mathrm{~mm}$ for aluminum (Livieri and Lazzarin, 2005; Lazzarin et al., 2003). A summary based on 900 experimental data obtained for the stainless steel construction has been accomplished, into a $\Delta \mathrm{W}-\mathrm{N}$ strip of the Scattering. The data include deliver different levels of welded connections, 3D models, head to head joints and welded joints profile with the goals, with fatigue the finger of the foot and the root of the weld (Berto and Lazzaein, 2014).

The aim of this work is to investigate theoretically, numeric and experimental two configurations of load carrying shear bolt welded joint in order to improve the resistance to tiredness in relation to the original. First one the schematic splice original welded has been reached and was identified the loading direction of fitting. Have been submitted then two deliver different. Some models accurate finite element have been carried out with the aim to investigate the condition of stress in the vicinity of the critical points in the butt welded. Some copies for the tests fatigue were also prepared in accordance with the geometric configurations defined. The data obtained after the tests have been re-analysed from the point of view of the SED and finally in comparison with the strip of the scattering proposed in the literature on the subject. 


\section{Material and Method}

Critical joints investigated in this work are those of the frame the press, which are necessary for the reinforcements to ensure adequate strength to tiredness. The plates in the frame are fixed to one another as shown in the illustration, to make a model that could easily be used for numeric analyses and tests of fatigue. The model is composed of two side panels, at which the two main plates are secured by means of the transverse Joints welded. Due to the complexity of the problem, it has not been possible to use a two-dimensional model. The section of the joint, perpendicular in relation to the direction of the load, can be described as being transverse acceleration and without task fillet welded joint faces. Is worthy of notice that the fitting is a task that carries the shear bolt welded in common: It is loaded the nominal load by shear, while the fingers of the feet of the welding operations and of the roots is subject at the local level to requests mix mode.

About 24 specimens have been carried out, 12 which corresponds to the geometry of 1 and 12 geometry of 2 . The tests fatigue have been carried out on a report by stress $\mathrm{R}=0$ and frequency $\mathrm{f}=10 \mathrm{~Hz}$, using a MTS 81 machine test. The specimens have been carried out by structural steel. FE analyses were made in the latter may apply the geometry 1 and 2 Geometry models the same draft load used in the tests of fatigue, in order to obtain the values of the SED.

\section{Test Specimens and Fatigue Tests}

Being the aim of the tests the characterisation of the mechanical part of the welded joint, the failure of the copies has been required to be avoided in other critical areas. An area with potential critical for resistance to tiredness of is that of the fillet radius the main, for which appear stress might well be described by the concentration of the theoretical factor of stress Kt.

According to Peterson (Pilkey and Pilkey, 2008), in order to minimize the value of $K_{t}$ has been used a file. Another to minimise the value of $K_{t}$ has been obtained by adopting a length suitable for the main plates $(150 \mathrm{~mm})$, in the light of the results of Troyani (2003) with regard to the length of the plates on the value of the Kt. Final amount of $K_{t}$ equal to 1.17 has been obtained (A final measure to improve the fatigue).

The resistance of the regions of the corner was to use a process of laser cut in order to obtain the main plates and to burnish the surface of the filets. The details are shown in the geometric parameters Fig. 1 Geometry 1 specimens and Fig. 2 Geometry 2 copies.
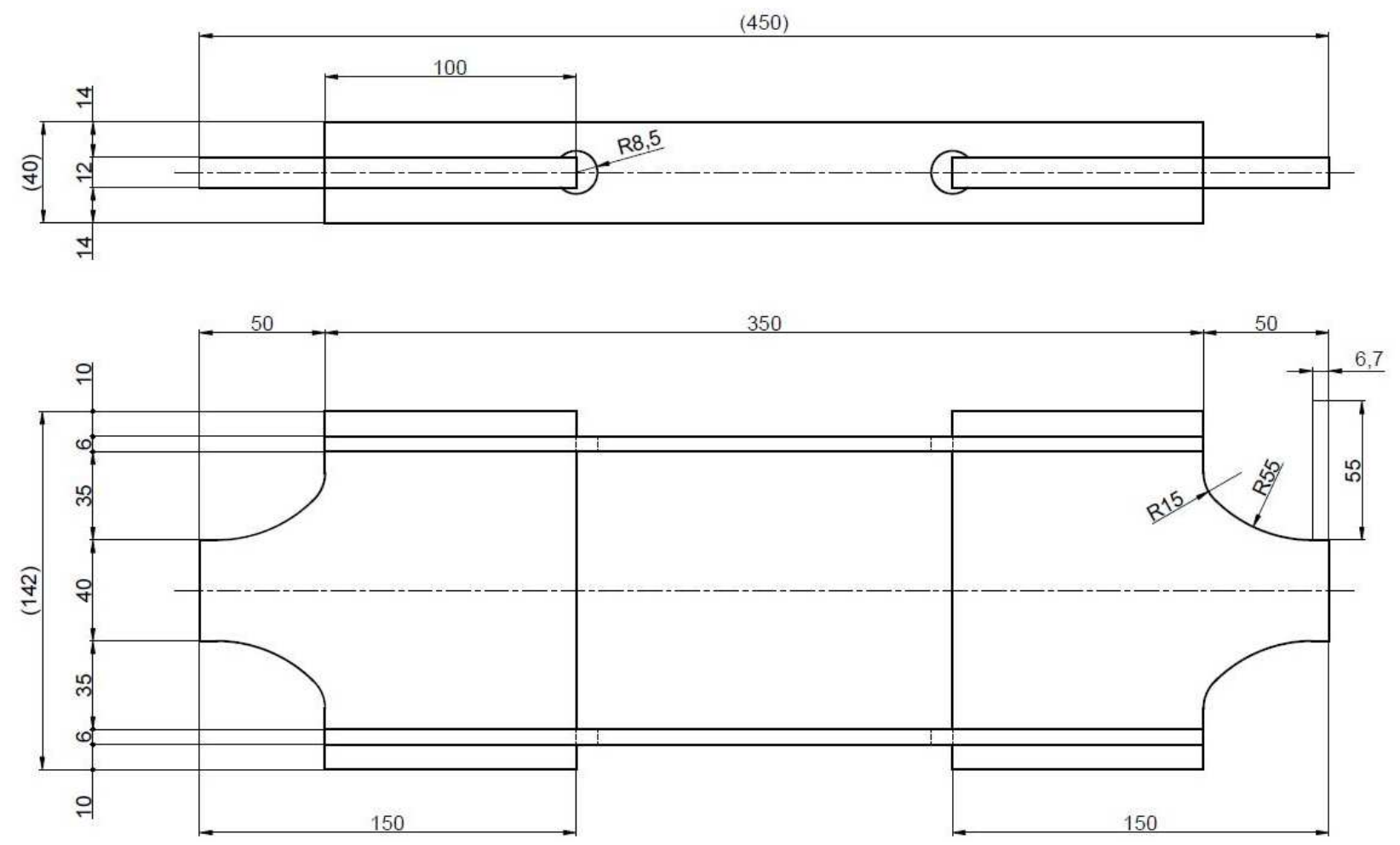

Fig. 1. Geometrical details of Geometry 1 specimen 
(450)
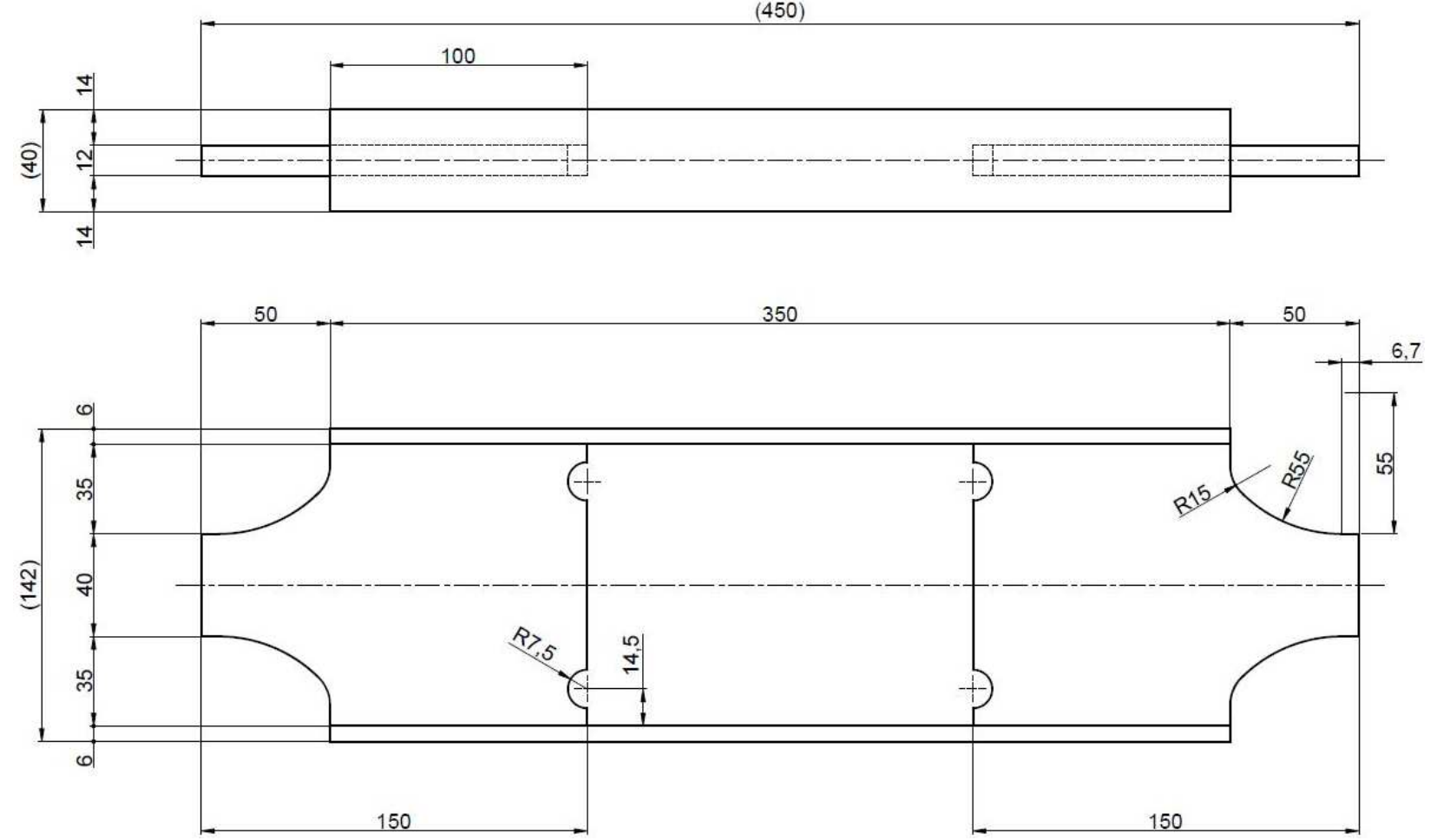

Fig. 2. Geometrical details of Geometry 2 specimen

\section{Numerical Models and FE Analyses}

Numerical models have been carried out using the software Ansys ${ }^{\circledR}$ 13.0. Due to the geometry of chosen, it was necessary to achieve a model of 3D. The type of component used in the model of the finished component is the component of brick with 20 nodes, called that solid186 in Ansys ${ }^{\circledR}$ 13.0. Only one eight of the specimen was modeled, in order to take advantage of symetry, the imposition of appropriate conditions of loading regarding the limits of the phantom. As explained in the Sections above, of peak of weld was shaped like a sharp object with the notch in the $\mathrm{V}$, with the angle of the equal to $135^{\circ}$ and the root of weld was shaped like a crack. Along the original string of a set of volumes of checking the centered on the finger of the foot of the weld and the root was carried out. Each volume has a radius 0.28 $\mathrm{mm}$ and depth equal to $0.28 \mathrm{~mm}$. The radius of the volume of the control has been chosen to be equal to the radius of the critical volume for the application of the EDI approach of steel, reported Livieri and Lazzarin (2005). The depth of each volume of control has been chosen to be equal to the radius (Lazzarin et al., $2008 \mathrm{~b}$ ). The volumes of checking the centered on the toe of weld have been discretizate with 10 elements; the centered on the root of the weld have been discretizate with 16 elements.

\section{Theory/Calculations}

Since the criterion Beltrami (1885), the density of the strain of energy has been set as a parameter to assess the resistance of the structural components; therefore, it has been used to formula different criteria of failure for parts and unnotched, made from materials which shows a ductile behaviour or brittle, charging in progress or static fatigue. A comprehensive revision of the criteria based on the stem of energy may be found in (Berto and Lazzarin, 2014).

An average density of the stem of energy (SED), the criterion has been proposed and formalized by Lazzarin and Zambardi $(2002 ; 2001)$ at the beginning for sharp, within a radius of zero, $\mathrm{V}$ nicks, in view of the problems two-dimensional stress ( plan or simple stem hypothesis) and has been studied and applied for the failures static and the assessment of the service life of the fatigue of the components of the jagged and welded subject to different conditions of loading (Berto and Lazzarin, 2014; 2009). The approach has subsequently been formalized for loading axis spider diagrams (Lazzarin et al., 2008b), as well as for the u- and blunt nicks V- (Lazzarin and Berto, 2005; Lazzarin et al., 2009), by means of the expressions obtained by Filippi et al. (2002) for the fields of stress before the blunt notches and has been successfully applied on a wide range of materials and the conditions of loading 
(Berto and Lazzarin, 2014; 2009). Recently, the EDI approach has been extended to the evaluation of the fatigue of specimens cut from Ti-6Of-4V under load axis spider diagrams (Berto et al., 2015a) and fatigue at high temperature alloy of copper-cobalt-beryllium (Berto et al., 2015b), 4013.9 CrMoV steel (Gallo and Berto, 2015a; 2015b) and level 2 (titanium Gallo et al., 2015).

The framework of analysis applied to achieve an expression form closed for the mean value of the SED in a volume of the control system shall be based on the expression of the total amount of the stem of the density of the energy consumption for a case of an isotropic material subjected to a linear law pad. Therefore, the value energy elastic deformation in a volume $\mathrm{V}$ is obtained by integrating the density of the stem of energy on the volume considered. The average density of the strain of energy is finally given by the energy elastic deformation over by volume. The expression of the form closed obtained for the SED is therefore depends on the analytical expressions taken into account for the distributions of stress on $\mathrm{V}$. the volume of control.

As mentioned above, the application of the local approach for the evaluation of the fatigue of the welded connections, is considered to be the worst case of parameters of weld geometric transformations. The radius of the finger of the foot of the weld is then presumed to be equal to zero and the region of the finger at the foot of the weld is set as a sharp object $\mathrm{V}$-notch. For problems V-notch two-dimensional (in the plan), the distributions of stress are given by the solution Williams", written in accordance with the wording Lazzarin and Tovo, in terms of the mode I and II NSIFs and volume over which the density of the stalk of consumption shall be media is a circular area radius $\mathrm{r} 0 \Omega$ centered at the tip of the notch and symmetrical in relation to bisector notch. Therefore, the expression of the EDI range for two-dimensional $\mathrm{V}$-notch proves to be:

$$
\Delta \bar{W}=\frac{e_{1}}{E} \cdot\left[\frac{\Delta K_{1}}{R_{0}^{1-\lambda_{1}}}\right]^{2}+\frac{e_{2}}{E} \cdot\left[\frac{\Delta K_{2}}{R_{0}^{1-\lambda_{2}}}\right]^{2}
$$

where, $E$ is the young of the material, $\lambda_{1}$ and $\lambda_{2}$ are the values of his own Williams (1952), $E_{1}$ and $E_{2}$ are two parameters which depend on the opening angle notch and $2 \mathrm{CX}$ on the hypothesis of the stem flat or stress considered plan. $K_{1}$ and $K_{2}$ are the stress factors Notch intensity (NSIFs) in accordance with the Gross and Mendelson (1972):

$$
\left\{\begin{array}{l}
K_{1}=\sqrt{2 \pi} \lim _{r \rightarrow 0} r^{\left(1-\lambda_{1}\right)}\left[\sigma_{\theta \theta}(r, \theta=0)\right] \\
K_{2}=\sqrt{2 \pi} \lim _{r \rightarrow 0} r^{\left(1-\lambda_{2}\right)}\left[\sigma_{r \theta}(r, \theta=0)\right]
\end{array}\right.
$$

In Equation $3 e_{3}$ depends on the Poisson's ratio and on the notch opening angle $2 \alpha$ and $K_{3}$ is the mode III NSIF (Frank et al., 2011; Remes et al., 2012):

$$
\Delta \bar{W}=\frac{e_{1}}{E} \cdot\left[\frac{\Delta K_{1}}{R_{0}^{1-\lambda_{1}}}\right]^{2}+\frac{e_{2}}{E} \cdot\left[\frac{\Delta K_{2}}{R_{0}^{1-\lambda_{2}}}\right]^{2}+\frac{e_{3}}{E} \cdot\left[\frac{\Delta K_{3}}{R_{0}^{1-\lambda_{3}}}\right]^{2}
$$

Only the antisimetry the voltage across the shear bolt out of plane is considered because of their behavior or singular, while the partial results symmetrical in a behavior non-singular (Lazzarin and Zappalorto, 2012). The expression of the range of stem density of energy is then updated as follows:

$$
K_{3}=\sqrt{2 \pi} \lim _{r \rightarrow 0} r^{\left(1-\lambda_{3}\right)}\left[\sigma_{\theta z}(r, \theta=0)\right]
$$

The parameter of material $R_{0}$ can be estimated by the equivalence of the expression for the critical value of the average of the SED obtained for a plot of land the butt welded in common, $\Delta W_{C}=\Delta \sigma_{A} / 2 E$, in order to quantify the influence of the process of welding on the material, with a critical value of the range SED obtained for a welded joint, with an opening angle $2 \alpha>102.6^{\circ}$ for which, in the case of charging status in the plan, only the way I contribute is considered, being the mode II contribute non-singular and mode of III contribute missing for particular condition: Charge.

For the three-dimensional problems, it is possible to use the field of estimated shelf request reported by Lazzarin and Zappalorto (2012), obtained by widespread use of the hypothesis stem plan, which leads to the breakdown of the equations of threedimensional ruling in a system in the case where an equation bi-elegance (problem in the plan) and a harmonic equation (out-of-plan problem) must be satisfied at the same time.

The SED expression is given by the sum of the SED for the problem in the plan and SED to the problem of the out-of-plan:

$\Delta \bar{W}_{C}=\frac{e_{1}}{E} \cdot\left[\frac{\Delta K_{1 A}}{R_{0}^{1-\lambda_{1}}}\right]^{2}$

The final expression for $R_{0}$ is then (Lazzarin and Zambardi, 2001).

Being $\Delta K_{1 A}$ the NSIF-based fatigue strength of steel welded joints $\left(211 \mathrm{MPa} \mathrm{mm}^{0.326}\right)$ and $\Delta \sigma_{A}$ the fatigue strength of the butt welded ground joint (155 $\mathrm{MPa}$ ), both related to $\mathrm{N}_{\mathrm{A}}=5 \times 10^{6}$ cycles with nominal load ratio $R=0$.

Introducing these values in the equation. (6), $R_{0}=$ $0.28 \mathrm{~mm}$ is obtained as the radius of the volume control for the thumb of welding, on which the SED must be on 
average for welded joints. For the root of the weld joints welded steel, modeled as a crack, Lazzarin et al. (2004) has obtained a value of $R_{0}=0.36 \mathrm{~mm}$, using the equivalence between the average EDI range obtained for a plot of land the butt welded in common with the expression of the range SED written for the case of $2 \alpha=$ 0 . It is then possible to take into account a value of critical RADIUS $R_{0}=0.28 \mathrm{~mm}$, as an approximation of engineering for both finger of the foot of the weld and the root of the weld in the assessment of the fatigue of the welded connections of steel:

$R_{0}=\left(\frac{\sqrt{2 e_{1}} \cdot \Delta K_{1 A}}{\Delta \sigma_{A}}\right)^{\frac{1}{1-\lambda_{1}}}$

\section{Results}

The results of the tests the fatigue are presented at the outset as regards the range of stress $\Delta \sigma=\sigma_{\max }-\sigma_{\min }$ compared with the number of cycles until the failure of $\mathrm{N}$, a scale double logarithmic for both geometry of 1 specimens (Fig. 3) and geometry of 2 copies (Fig. 4). The range of stress refers to the net section of the plates side $\left(480 \mathrm{~mm}^{2}\right)$. The results of the tests have been developed using statistical a distribution of the logarithmic normal. There have been no samples of "run-out" (i.e., failed to fatigue took place at a number of minor cycle of $5 \times 10^{6}$ cycles for all copies). Strip of the scattering defined by the lines with 10 and $90 \%$ on the likelihood of survival (tape scatter Haibach) is represented graphically in addition to the curve in relation with a probability of survival of $50 \%$ (an $\mathrm{S} / \mathrm{N}-$ curve). The average value range of stress corresponding to two million cycles, the slope $\mathrm{k}$ reverse and the index of the abatement $T_{\sigma}$ (defined as the ratio between the range of stress at $10 \%$ of the likelihood of survival and the range of stress at the $90 \%$ probability of survival) are provided in Fig. 3 and 4.

For the geometry of the 1 specimen, a resistance to the fatigue $\Delta \sigma=44 \mathrm{MPa} N=2 \cdot 10^{6}$ and an index of the scattering $T_{\sigma}=1.149$ were obtained; the geometry 2 copies, a resistance to the fatigue $\Delta \sigma=100 \mathrm{MPa}$ at $N$ $=2 \cdot 10^{6}$ and an index of the scattering $T_{\sigma}=1.361$ have been obtained. The resistance to tiredness corresponding to the $N=5 \cdot 10^{6}$ is $\Delta \sigma=33 \mathrm{MPa}$ for the geometry of the 1 specimens and $\Delta \sigma=74 \mathrm{MPa}$ for the geometry of the 2 copies.

The ski is reverse, respectively, $k=3.30$ and $k=3.09$. Values range of stress of reference reference is made to a life to the fatigue of $10^{6}, 2 \cdot 10^{6}$ and $5 \cdot 10^{6}$ cycles are given in explicitly for a probability of survival of 10, 50 and $90 \%$, together with the slope $\mathrm{k}$ vice versa and the index of the scattering $T_{\sigma}$.

A summary final as regards the density of the stem of the local energy is presented in Fig. 5, in the case in which the value range of the SED $\Delta \mathrm{W}$ compared with the number of cycles until the failure of $\mathrm{N}$ is displayed in the graphic in a double scale logarithmic Slide Rule. The SED values have been obtained in the area of the most critical of joints which are applicable to the model number of each copy values from the range of stress applied in tests of fatigue. In Fig. 5 strip of the scattering which summarizes the data obtained from the fatigue for welded joints, structural steel have been superimposed over the results of this survey, to make a direct comparison.

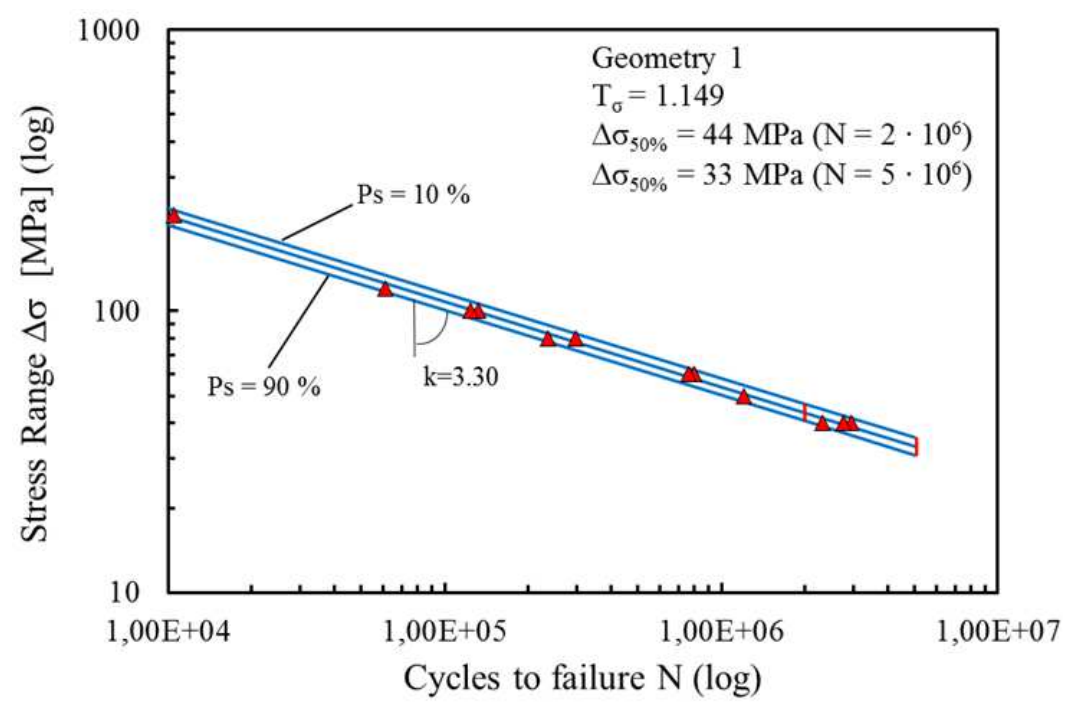

Fig. 3. Wöhler curve and Haibach scatter band for fatigue data of Geometry 1 specimens 


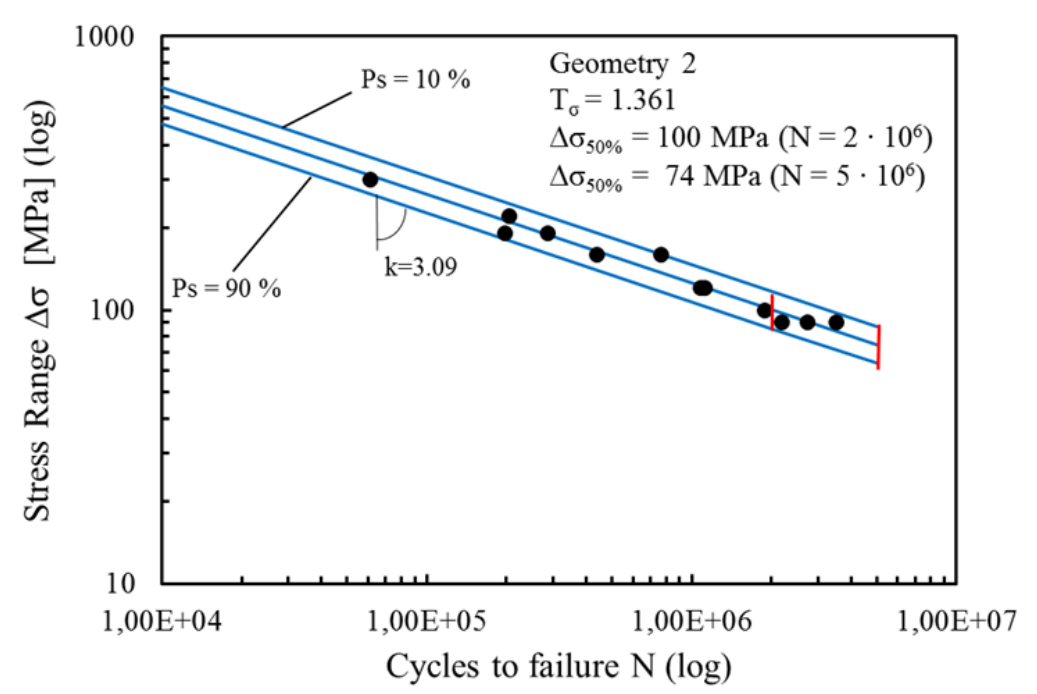

Fig. 4. Wöhler curve and Haibach scatter band for fatigue data of Geometry 2 specimens

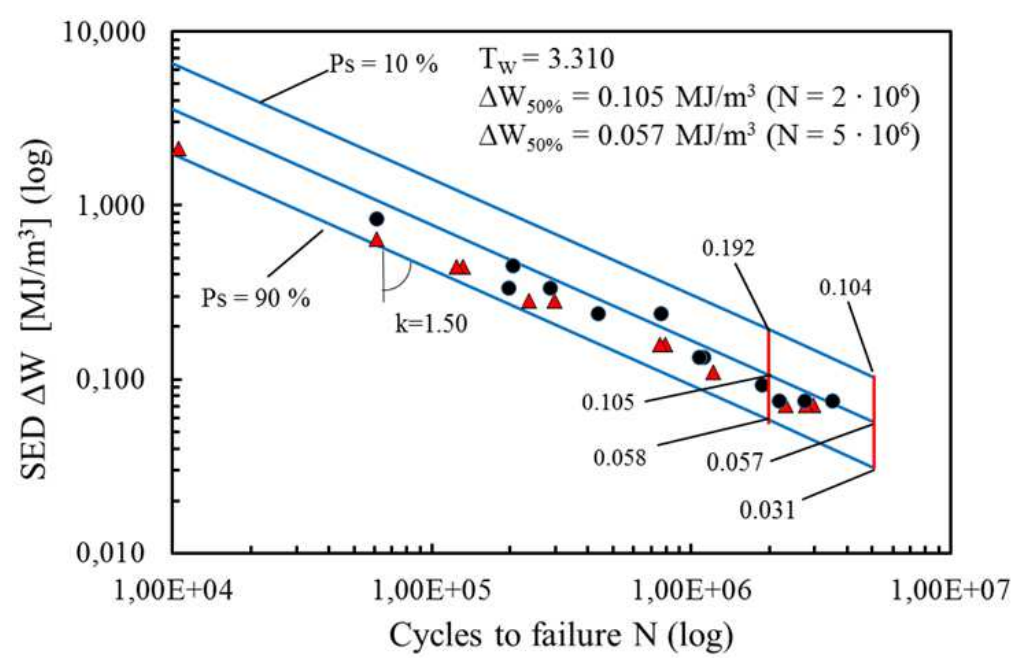

Fig. 5. Current research fatigue life data compared with the SED scatter band reported in literature

\section{Discussion}

The analyses of the initial numeric allow you to compare the behaviour of the different proposed stressed, as well as to identify the lowest point of the critical welds taken into account. Is worthy of notice that through the approach to the stem density of energy (SED), a direct comparison between the fingers of the legs of the weld and the roots is possible. The results of the analyses of the difference numeric indicates that the critical point on the geometry of the 1 joint welding is the root, in the same way as the initial geometry, while the critical point on the geometry of the 2 is the toe side. For the purpose of optimising behaviour of the fatigue of the joint welded, should be desirable to have the initiation of cracks in a visible Geometry 2 is therefore preferable geometry of the 1 for the purpose of an access and easy and inspection rules in the critical part of the press.

Quantitative results obtained as a result of the comparison are confirmed by the tests of fatigue: Initiate cracks occurs at the points identified as the most critical in the analyses of the previous numeric. More than that, resistance to tiredness the geometry of the 2 is significantly higher: In numerical analyses, under a value equal to the tasks, the maximum value of the SED at the foot of the side on the geometry of the 2 in common was approximately five times smaller than the maximum value at the root of the geometry 1 . The best behaviour of the fatigue the geometry of the 2 in common was then quantitatively expected. The data of the resistance to tiredness expressed as regards the range of stress, the indices of the scattering obtained for both the geometries were extremely low. 
Despite the great differences in the resistance to tiredness the second vehicle geometries welded connections, has not been possible to summarise the data obtained in a single curve through the approach to the average density of the strain of energy. Data of fatigue obtained as regards the SED shall be within the band of the scattering previously proposed in the specialized literature for steel construction welded. Some Recent Studies interesting were focused on the effect of the voltages on the SED values (Ferro et al., 2006; Ferro, 2012; 2014; Ferro et al., 2016a; 2016b; 2016c; Ferro and Berto, 2016) and the matter is very important for the practical applications and shall be taken into account also in the future work. In addition, some recent developments can be found in Refs (Gallo et al., 2016a; 2016b; Berto and Gallo, 2015; Gallo and Berto, 2015c; Berto et al., 2014a; 2014b), which deals with high temperature and the fatigue of metal.

\section{Conclusion}

The SED approach has been used to compare the behaviour of the fatigue of the load carrying Joints welded shear characterized by different vehicle geometries, for the purpose of optimising the design of a structural part of a mechanical. In particular, the interdiction original and two- geometries have been taken into account. It has been possible to achieve a quantitative evaluation by FE analyses, application of the numerical models a task arbitrarily, identifying areas most critical for each model and thus by comparing the size of the value of the SED in these areas.

Tests of fatigue have been carried out on samples of the two- geometries proposed earlier, made of steel. The results of the tests of fatigue seemed to be an excellent agreement with the expectations of the model and the investigations of the numeric. Despite the great differences in the resistance to tiredness, data of life to fatigue of both the geometries expressed in terms of the SED could be in a single strip summed up the Scattering. More than that, the data of life to fatigue expressed in terms of the decrease in average density of energy of the stem in-band scattering proposed in the specialized literature for welded joints made of steel.

\section{Acknowledgement}

This text was acknowledged and appreciated by Professor Guanying Chen Harbin Institute of Technology and SUNY Buffalo China, Associate Professor Aniello Riccio SECONDA UNIVERSITA' DEGLI STUDI DI NAPOLI Italy, Dr. (Ms.) Shweta Agarwala Senior Research Scientist at Singapore Center for 3D Printing Nanyang Technological University Singapore, whom we thanks and in this way.

\section{Author's Contributions}

All the authors contributed equally to prepare, develop and carry out this manuscript.

\section{Ethics}

This article is original. Authors declare that are not ethical issues that may arise after the publication of this manuscript.

\section{References}

Atzori, B., 1985. Fracture mechanics or notch effect for fatigue design. Proceedings of the 13th Conference Ital. Soc. Strain Anal., (SSA' 85), Bergamo, Italy, pp: 294-307.

Atzori, B., P. Lazzarin and R. Tovo, 1999. From a local stress approach to fracture mechanics: A comprehensive evaluation of the fatigue strength of welded joints. Fatigue Fract. Eng. Mater. Struct., 22: 369-381.

DOI: $10.1046 /$ j.1460-2695.1999.00179.x

Beltrami, E., 1885. Sulle condizioni di resistenza dei corpi elastici. Nuovo Cim., 18: 145-145. DOI: $10.1007 / \mathrm{BF} 02824697$

Berto, F. and P. Gallo, 2015. Extension of linear elastic strain energy density approach to high temperature fatigue and a synthesis of cu-be alloy experimental tests. Eng. Sol. Mech., 3: 111-116.

DOI: $10.5267 /$ j.esm.2015.1.004

Berto, F. and P. Lazzarin, 2009. A review of the volume-based strain energy density approach applied to V-notches and welded structures. Theor. Applied Fract. Mech., 52: 183-194.

DOI: 10.1016/j.tafmec.2009.10.001

Berto, F. and P. Lazzarin, 2014. Recent developments in brittle and quasi-brittle failure assessment of engineering materials by means of local approaches. Mater. Sci. Eng. R, 75: 1-48. DOI: 10.1016/j.mser.2013.11.001

Berto, F., 2016. Tilted lateral V-notches with root hole subjected to in-plane mixed mode loading: Fictitious notch rounding concept. Mater. Des., 89: 913-927. DOI: 10.1016/j.matdes.2015.10.036

Berto, F., P. Lazzarin and D. Radaj, 2012. Fictitious notch rounding concept applied to $\mathrm{V}$-notches with root holes subjected to in-plane shear loading. Eng. Fract. Mech., 79: 281-294. DOI: 10.1016/j.engfracmech.2011.11.007

Berto, F., P. Lazzarin and P. Gallo, 2014a. Hightemperature fatigue strength of a copper-cobaltberyllium alloy. J. Strain Anal. Eng. Des., 49: 244-256. DOI: $10.1177 / 0309324713511804$ 
Berto, F., P. Gallo and P. Lazzarin, 2014b. High temperature fatigue tests of un-notched and notched specimens made of 40CrMoV13.9 steel. Mater. Design, 63: 609-619.

DOI: 10.1016/j.matdes.2014.06.048

Berto, F., A. Campagnolo and P. Lazzarin, 2015a. Fatigue strength of severely notched specimens made of Ti-6Al-4V under multiaxial loading. Fatigue Fract. Eng. Mater. Struct., 38: 503-517. DOI: $10.1111 /$ ffe. 12272

Berto, F., P. Gallo and P. Lazzarin, 2015b. High temperature fatigue tests of a $\mathrm{Cu}-\mathrm{Be}$ alloy and synthesis in terms of linear elastic strain energy density. Key Eng. Mater., 627: 77-80.

DOI: 10.4028/www.scientific.net/KEM.627.77

Boukharouba, T., T. Tamine, L. Niu, C. Chehimi and G. Pluvinage, 1995. The use of notch stress intensity factor as a fatigue crack initiation parameter. Eng. Fract. Mech., 52: 503-512. DOI: 10.1016/0013-7944(94)00242-A

BS7608, 1993. Fatigue design and assessment of steel structures-code of practice. British Standards Institution, London.

Cristofori, A., P. Livieri and R. Tovo, 2009. An application of the implicit gradient method to welded structures under multiaxial fatigue loadings. Int. J. Fatigue, 31: 12-19. DOI: 10.1016/j.ijfatigue.2008.05.007

ECCS/CECM/EKS, 1985. Recommendations for the fatigue design of steel structures. ECCS, Brussels.

Ferro, P. and F. Berto, 2016. Quantification of the influence of residual stresses on fatigue strength of al-alloy welded joints by means of the local strain energy density approach. Strength Mater., 48: 426-436. DOI: 10.1007/s11223-016-9781-0

Ferro, P., 2012. Influence of phase transformations on the asymptotic residual stress distribution arising near a sharp V-notch tip. Modell. Simul. Mater. Sci. Eng., 20: 085003-085003.

DOI: $10.1088 / 0965-0393 / 20 / 8 / 085003$

Ferro, P., 2014. The local strain energy density approach applied to pre-stressed components subjected to cyclic load. Fatigue Fract. Eng. Mater. Struct., 37: 1268-1280. DOI: 10.1111/ffe.12211

Ferro, P., F. Berto and P. Lazzarin, 2006. Generalized stress intensity factors due to steady and transient thermal loads with applications to welded joints. Fatigue Fract. Engng. Mater. Struct., 29: 440-453. DOI: 10.1111/j.1460-2695.2006.01015.x

Ferro, P., F. Berto and N.M. James, 2016a. Asymptotic residual stresses in butt-welded joints under fatigue loading. Theor. Applied Fract. Mech., 83: 114-124. DOI: $10.1016 /$ j.tafmec.2016.02.002
Ferro, P., F. Berto and T. Borsato, 2016b. Thermal loadinduced notch stress intensity factor derived from averaged strain density. Proceedings of the $21 \mathrm{st}$ European Conference on Fracture, Jun. 20-24, Procedia Structural Integrity, pp: 2367-2374

Ferro, P., F. Berto, M.N. James and T. Borsato, 2016c. Review of recent advances in local approaches applied to pre-stressed components under fatigue loading. Proceedings of the 21st European Conference on Fracture, Jun. 20-24, Procedia Structural Integrity, pp: 3467-3474.

Filippi, S., P. Lazzarin and R. Tovo, 2002. Developments of some explicit formulas useful to describe elastic stress fields ahead of notches in plates. Int. J. Solids Struct., 39: 4543-4565. DOI: 10.1016/S0020-7683(02)00342-6

Frank, D., H. Remes and J. Romanoff, 2011. Fatigue assessment of laser stake-welded T-joints. Int. J. Fatigue. 33: 102-114. DOI: $10.1016 /$ j.ijfatigue.2010.07.002

Frank, D., H. Remes and J. Romanoff, 2013. J-integralbased approach to fatigue assessment of laser stakewelded T-joints. Int. J. Fatigue, 47: 340-350. DOI: 10.1016/j.ijfatigue.2012.09.019

Gallo, P. and F. Berto, 2015a. Advanced materials for applications at high temperature: Fatigue assessment by means of local strain energy density. Adv. Eng. Mater. DOI: 10.1002/adem.201500547

Gallo, P. and F. Berto, 2015b. High temperature fatigue tests and crack growth in 40CrMoV13.9 notched components. Fract. Struct. Integr., 9: 180-189. DOI: 10.3221/IGF-ESIS.34.19

Gallo, P. and F. Berto, 2015c. Influence of surface roughness on high temperature fatigue strength and cracks initiation in 40CrMoV13.9 notched components. Theor. Applied Fract. Mech., 80: 226-234. DOI: 10.1016/j.tafmec.2015.07.003

Gallo, P., F. Berto and P. Lazzarin, 2015. High temperature fatigue tests of notched specimens made of titanium Grade 2. Theor. Applied Fract. Mech., 76: 27-34. DOI: 10.1016/j.tafmec.2014.12.007

Gallo, P., F. Berto and G. Glinka, 2016a. Generalized approach to estimation of strains and stresses at blunt V-notches under non-localized creep. Fatigue Fract. Eng. Mater. Struct., 39: 292-306. DOI: $10.1111 / \mathrm{ffe} .12374$

Gallo, P., T. Sumigawa, T. Kitamura and F. Berto, 2016b. Evaluation of the strain energy density control volume for a nanoscale singular stress field. Fatigue Fract. Eng. Mater. Struct., 39: 1557-1564. DOI: $10.1111 /$ ffe. 12468

Gross, B. and A. Mendelson, 1972. Plane elastostatic analysis of V-notched plates. Int. J. Fract. Mech., 8: 267-276. DOI: 10.1007/BF00186126 
Gurney, T.R., 1991. The Fatigue Strength of Transverse Fillet Welded Joints: A Study of the Influence of Joint Geometry. 1st Edn., Elsevier, Cambridge, ISBN-10: 0857093258, pp: 112.

Hobbacher, A., 2006. Recommendations for fatigue design of welded joints and components (update). IIW Doc XIII-1965-03/XV-1127-03.

Karakas, Ö., C. Morgenstern and C.M. Sonsino, 2007. Schwingfeste Auslegung von Schweißverbindungen aus der Magnesiumknetlegierung AZ31(ISO-MgAl3Zn1) mit dem Konzept der fiktiven Ersatzradien von $\mathrm{rf}=1,0 \mathrm{~mm}$ und $0,05 \mathrm{~mm}$. Materwiss. Werksttech, 38: 603-612. DOI: 10.1002 /mawe. 200700182

Karakas, Ö., C. Morgenstern and C.M. Sonsino, 2008. Fatigue design of welded joints from the wrought magnesium alloy AZ31 by the local stress concept with the fictitious notch radii of $\mathrm{rf}=1.0$ and 0.05 mm. Int. J. Fatigue, 30: 2210-2219.

DOI: 10.1016/j.ijfatigue.2008.05.017

Lassen, T., 1990. The effect of the welding process on the fatigue crack-growth. Weld. J., 69: S75-S81.

Lazzarin, P. and R. Tovo, 1998. A notch intensity factor approach to the stress analysis of welds. Fatigue Fract. Eng. Mater. Struct., 21: 1089-1103. DOI: 10.1046/j.1460-2695.1998.00097.x

Lazzarin, P. and F. Berto, 2005. Some expressions for the strain energy in a finite volume surrounding the root of blunt V-notches. Int. J. Fract., 135: 161-185. DOI: $10.1007 / \mathrm{s} 10704-005-3943-6$

Lazzarin, P. and M. Zappalorto, 2012. A threedimensional stress field solution for pointed and sharply radiused $\mathrm{V}$-notches in plates of finite thickness. Fatigue Fract. Eng. Mater. Struct., 35: 1105-1119.

DOI: 10.1111/j.1460-2695.2012.01698.x

Lazzarin, P. and R. Zambardi, 2001. A finite-volumeenergy based approach to predict the static and fatigue behavior of components with sharp Vshaped notches. Int. J. Fract., 112: 275-298.

DOI: $10.1023 / \mathrm{A}: 1013595930617$

Lazzarin, P. and R. Zambardi, 2002. The equivalent strain energy density approach re-formulated and applied to sharp V-shaped notches under localized and generalized plasticity. Fatigue Fract. Eng. Mater. Struct., 25: 917-928.

DOI: 10.1046/j.1460-2695.2002.00543.x

Lazzarin, P., C.M. Sonsino and R. Zambardi, 2004. A notch stress intensity approach to assess the multiaxial fatigue strength of welded tube-to-flange joints subjected to combined loadings. Fatigue Fract. Eng. Mater. Struct., 27: 127-140.

DOI: 10.1111/j.1460-2695.2004.00733.x
Lazzarin, P., F. Berto and D. Radaj, 2009. Fatiguerelevant stress field parameters of welded lap joints: Pointed slit tip compared with keyhole notch. Fatigue Fract. Eng. Mater. Struct., 32: 713-735. DOI: $10.1111 /$ j.1460-2695.2009.01379.x

Lazzarin, P., F. Berto and M. Zappalorto, 2010. Rapid calculations of notch stress intensity factors based on averaged strain energy density from coarse meshes: Theoretical bases and applications. Int. J. Fatigue, 32: 1559-1567.

DOI: 10.1016/j.ijfatigue.2010.02.017

Lazzarin, P., F. Berto, F.J. Gomez and M. Zappalorto, 2008a. Some advantages derived from the use of the strain energy density over a control volume in fatigue strength assessments of welded joints. Int. J. Fatigue, 30: 1345-1357.

DOI: 10.1016/j.ijfatigue.2007.10.012

Lazzarin, P., P. Livieri, F. Berto and M. Zappalorto, 2008b. Local strain energy density and fatigue strength of welded joints under uniaxial and multiaxial loading. Eng. Fract. Mech., 75: 1875-1889. DOI: $10.1016 /$ j.engfracmech.2006.10.019

Lazzarin, P., F. Berto, M. Elices and J. Gómez, 2009. Brittle failures from $\mathrm{U}$ - and $\mathrm{V}$-notches in mode I and mixed, I + II, mode: A synthesis based on the strain energy density averaged on finite-size volumes. Fatigue Fract. Eng. Mater. Struct., 32: 671-684. DOI: $10.1111 /$ j.1460-2695.2009.01373.x

Lazzarin, P., T. Lassen and P. Livieri, 2003. A notch stress intensity approach applied to fatigue life predictions of welded joints with different local toe geometry. Fatigue Fract. Eng. Mater. Struct., 26: 49-58. DOI: 10.1046/j.1460-2695.2003.00586.x

Livieri, P. and P. Lazzarin, 2005. Fatigue strength of steel and aluminium welded joints based on generalised stress intensity factors and local strain energy values. Int. J. Fract., 133: 247-276. DOI: $10.1007 / \mathrm{s} 10704-005-4043-3$

Livieri, P. and R. Tovo, 2009. The use of the JV parameter in welded joints: Stress analysis and fatigue assessment. Int. J. Fatigue, 31: 153-163. DOI: 10.1016/j.ijfatigue.2008.06.007

Livieri, P., 2008. Use of J-integral to predict static failures in sharp V-notches and rounded U-notches. Eng. Fract. Mech., 75: 1779-1793. DOI: $10.1016 /$ j.engfracmech.2007.01.022

Livieri, P., E. Salvati and R. Tovo, 2016. A non-linear model for the fatigue assessment of notched components under fatigue loadings. Int. J. Fatigue, 82: 624-633. DOI: 10.1016/j.ijfatigue.2015.09.019

Maddox, S.J., 1987. The Effect of Plate Thickness on the Fatigue Strength of Fillet Welded Joints. 1st Edn., Welding Institute, Cambridge, ISBN-10: 0853002088, pp: 48. 
Maggiolini, E., P. Livieri and R. Tovo, 2015. Implicit gradient and integral average effective stresses: relationships and numerical approximations. Fatigue Fract. Eng. Mater. Struct., 38: 190-199. DOI: $10.1111 /$ ffe. 12216

Pilkey, W.D. and D.F. Pilkey, 2015. Peterson's stress concentration factors.

Radaj, D., 1990. Design and Analysis of Fatigue Resistant Welded Structures. 1st Edn., Woodhead Publishing, Abington, ISBN-10: 1855730049, pp: 378.

Radaj, D., C.M. Sonsino and W. Fricke, 2006. Fatigue Assessment of Welded Joints by Local Approaches. 2nd Edn., Woodhead, Cambridge, ISBN-10: 1855739488, pp: 639.

Radaj, D., F. Berto and P. Lazzarin, 2009. Local fatigue strength parameters for welded joints based on strain energy density with inclusion of small-size notches. Eng. Fract. Mech., 76: 1109-1130. DOI: 10.1016/j.engfracmech.2009.01.009

Radaj, D., P. Lazzarin and F. Berto, 2013. Generalised Neuber concept of fictitious notch rounding. Int. J. Fatigue, 51: 105-115. DOI: 10.1016/j.ijfatigue.2013.01.005

Remes, H., P. Varsta and J. Romanoff, 2012. Continuum approach to fatigue crack initiation and propagation in welded steel joints. Int. J. Fatigue, 40: 16-26. DOI: 10.1016/j.ijfatigue.2012.01.007

Singh, P., D. Achar, B. Guha and H. Nordberg, 2003. Fatigue life prediction of gas tungsten arc welded AISI 304L cruciform joints with different LOP sizes. Int. J. Fatigue, 25: 1-7.

DOI: $10.1016 / \mathrm{S} 0142-1123(02) 00067-1$
Susmel, L. and D. Taylor, 2012. A critical distance/plane method to estimate finite life of notched components under variable amplitude uniaxial/multiaxial fatigue loading. Int. J. Fatigue, 38: 7-24. DOI: $10.1016 /$ j.ijfatigue.2011.11.015

Susmel, L. and D. Taylor, 2011. The theory of critical distances to estimate lifetime of notched components subjected to variable amplitude uniaxial fatigue loading. Int. J. Fatigue, 33: 900-911. DOI: 10.1016/j.ijfatigue.2011.01.012

Susmel, L., H. Askes, T. Bennett and D. Taylor, 2013. Theory of critical distances versus gradient mechanics in modelling the transition from the short to long crack regime at the fatigue limit. Fatigue Fract. Eng. Mater. Struct., 36: 861-869. DOI: $10.1111 /$ ffe. 12066

Tovo, R. and P. Livieri, 2012. Predicting the fatigue strength of small thickness welded joints using the implicit gradient method. Weld. Int., 26: 839-844. DOI: $10.1080 / 09507116.2011 .592700$

Troyani, N., 2003. Simultaneous considerations of length and boundary conditions on theoretical stress concentration factors. Int. J. Fatigue, 25: 353-355. DOI: $10.1016 / \mathrm{S} 0142-1123(02) 00139-1$

Verreman, Y. and B. Nie, 1996. Early development of fatigue cracking at manual fillet welds. Fatigue Fract. Eng. Mater. Struct., 19: 669-681. DOI: 10.1111/j.1460-2695.1996.tb01312.x

Williams, M.L., 1952. Stress singularities resulting from various boundary conditions in angular corners on plates in extension. J. Appl. Mech., 19: 526-528. 